\title{
Patient satisfaction with care by dental therapists
}

\author{
N. Sun, ${ }^{1}$ G. Burnside ${ }^{2}$ and R. Harris ${ }^{3}$
}

VERIFIABLE CPD PAPER

- Gives evidence of a difference in patient satisfaction with care given by dental therapists, compared to dentists.

- Differences were not confined to patient satisfaction with informationcommunication, but differences in patient satisfaction with technical competence and understandingacceptance were also seen.

- Opens up a new line of research relating to why such differences are apparent.

\begin{abstract}
Introduction Patient reported outcomes of care are increasingly used as a measure of the quality of care. There has been a recent expansion in the number of dental therapists trained in the UK, and with legislation now permitting therapists to take on a wider role in dental practice, patients' perceptions about quality of care provided by therapists is an important issue. Objectives To investigate whether there were any differences in patient satisfaction after a visit to a therapist, compared to a visit to a dentist. Method A ten-item scale of patient satisfaction (Dental Visit Satisfaction Scale), which provides an outcome measure of overall patient satisfaction as well as three sub-scale outcomes (informationcommunication; understanding-acceptance; and technical competence) was used. A total of 240 questionnaires were given to consecutive patients attending an appointment with a therapist and 400 questionnaires were given to patients attending dentists, in eight different dental practices. Results Four hundred and thirty-one (67.3\%) questionnaires were returned. Patients attending therapists were found to have a significantly higher level of overall satisfaction $(p<0.001)$ and also in all three sub-scales $(\mathrm{p}<0.001)$, than those attending appointments with dentists. Conclusion Although a clear distinction in patient satisfaction according to the type of provider was found, the reasons behind this finding are unclear, and so care needs to be taken in interpreting the results, with further work undertaken to explore this phenomenon more fully.
\end{abstract}

\section{INTRODUCTION}

Dental practice is changing. The vision for the future is that the practice of dentistry should become more team-based. ${ }^{1}$ A succession of policy documents in recent years has outlined a growing role for dental care professionals $^{2,3}$ (DCPs), and in some dental practices in the UK this has become a reality. Growing numbers of dental therapists are being trained, and their role has broadened, due to recent changes in legislation. ${ }^{4}$ Prior to July 2006, UK dental therapists as well as dental hygienists and dental nurses operated according to lists of permitted duties; in the case of dental therapists, this restricted their role to the provision of scale and polish, preventive care, simple fillings and extraction of deciduous teeth.

\footnotetext{
${ }^{1}$ Research Associate, ${ }^{2}$ Lecturer in Dental Statistics, ${ }^{3}$ Senior Clinical Lecturer/Honorary Consultant, School of Dental Sciences, Liverpool University Dental Hospital, Pembroke Place, Liverpool, L3 5PS ${ }^{*}$ Correspondence to: Dr Rebecca Harris Email: harrisrv@liverpool.ac.uk
}

\section{Online article number E9}

Refereed Paper - accepted 9 October 2009

DOI: $10.1038 /$ sj.bdj.2010.209

${ }^{\circ}$ British Dental Journal 2010; 208: E9
However a wider remit is now permitted within a new regulatory framework, with activities undertaken by all DCP groups currently determined by reference to their training and competence. ${ }^{4}$ This considerably frees previous restrictions to innovations in dental team working, allowing for a further expansion of the role played by DCPs in dental practice.

The system of regulation roles undertaken by DCPs is now more in line with the situation which exists in general medical practice. ${ }^{5}$ For many years general medical practitioners have been able to use nurses to innovate, without a law being written to allow it. The number of practice nurses more than trebled between 1985 and $1991,{ }^{6}$ with many performing tasks previously only undertaken by doctors. There is also evidence that this expansion in skill mix has brought gains in terms of quality of patient care. Using quality scores reflecting ten clinical domains and holistic care in the 2004-5 UK general medical contract, larger clinical teams were found to have higher quality scores, ${ }^{7}$ although this may not necessarily be due to the doctor-nurse substitution, but perhaps the greater accountability which exists in a larger team, and greater numbers of more recently qualified staff. There is also some suggestion that even if clinical outcomes might be similar for nurses and doctors, patient satisfaction is higher for nurse-led care. ${ }^{8}$ However, there is an acknowledgement that the evidence is weak in this area, given that only one study has been powered to assess equivalence of care. ${ }^{8}$ Consequently there are calls for more studies to investigate the impact of skill mix on outcomes, as perceived by the patient, ${ }^{9}$ both within dentistry and in healthcare more generally.

Certainly, part of the vision put forward for the dental team was that, in increasing team working within dental practice, the quality of patient care would be enhanced. ${ }^{2}$ Several studies have previously shown that the quality of work by dental therapists is at least of a similar standard to dentists. ${ }^{10,11}$ However, very little evidence exists in relation to patient reported outcomes of care in relation to the use of skill mix in dental practice, 
even though this is against a background of a general shift towards consumerism in all aspects of public service. ${ }^{12}$

Consumer satisfaction with healthcare has gained widespread recognition as a measure of quality since the publication of the 1983 Management Inquiry and its call for the collation of user opinion, ${ }^{13}$ and there is now a common consensus that care cannot be viewed as high quality unless the patient is satisfied..$^{14}$ Measurement of patient satisfaction is therefore seen as a vital aspect of evaluating the overall quality of care.

Unfortunately, outlining the importance of taking into account patient satisfaction is rather easier than defining the construct and designing appropriate instruments to measure it. Human satisfaction is a complex concept that is related to a number of factors including lifestyle, past experiences and future expectations, and the values of both the individual and society. ${ }^{15}$ Customer evaluation of a product, for example, is known to be influenced by both customer effort and expectation. ${ }^{16}$ The concept of patient satisfaction was originally derived from consumer satisfaction, and there is strong interlinking between the two concepts. In many cases, the two terms are used inter-changeably. Recent definitions see consumer satisfaction as a complex evaluative process that 'the consumption experience was at least as good as it supposed to be. ${ }^{17}$ Three important elements can be extracted from this definition: that the concept involves expectation, perception and comparison.

In the literature there are a large number of studies describing ways of evaluating patient satisfaction by means of different questionnaires and psychometric tests. ${ }^{18}$ Within the dental context specific measures have been developed to tailor these to the setting, and of the measures available, the Dental Visit Satisfaction Scale (DVSS) is one of the most frequently used. ${ }^{19}$ Originally developed from the Medical Interview Satisfaction Scale ${ }^{20}$ which was based on patients' perceptions of the physicians directly following a medical interview and examination, the DVSS includes three dimensions which are assumed to reflect the cognitive, affective and behavioural satisfaction of patients, as well as an overall general satisfaction score. The three dimensions included are: information-communication, understanding-acceptance and technical competence. The DVSS has the advantages that it is a short and easy to use measure (ten items only), and therefore practical to use in a dental practice setting, as well having been previously shown to have relatively high validity and reliability. ${ }^{19}$ The DVSS focuses on a patient's perception on a specific dental visit. The aim of this study therefore was to investigate whether there were any differences in patient satisfaction after a visit to a dental therapist, compared to a visit to a dentist.

\section{METHOD}

This study was part of a wider multiplecase study concerned with the use of dental therapists in dental practices. Case study research is a recognised form of empirical inquiry which investigates complex issues by detailed contextual analysis in real life situations using multiple sources of evidence. ${ }^{21}$ Patient satisfaction was one aspect of the use of dental therapists studied, with the cases under investigation being dental practices. Under case study methodology, the case selection is determined by certain parameters which identify cases as either being unique in some ways or typical. The parameters used in this study were the size of dental practice, whether a dental therapist was employed, and the type of model of dental therapist delegation and financing. Thus a purposive sampling methodology was used to identify the dental practices to be studied, using a combination of inductive and deductive approaches.

Eight dental practices were chosen, all in the North West of England. One of these provided care almost entirely on an NHS basis, and the others provided a mixture of NHS and private care, up to a split of $60 \%$ NHS care, $40 \%$ private. Six of the practices employed at least one dental therapist. An additional two practices with no dental therapist in the team were also studied. In two of the six practices employing dental therapists, work was delegated to the dental therapist(s) by only some of the dentists in the teams. Table 1 shows the numbers of dentists and dental therapists in each of the teams studied. Across the eight practices, a total of 11 dental therapists (ten female, one male) were employed. With the exception of one therapist, all the dental therapists were originally trained as dental nurses. All 11 therapists were relatively newly qualified.

Three of the eight dental practices involved in the study (practices 1,2 and 5) were located in relatively low socioeconomic areas, ranking in the top 20\% most deprived areas according to quintiles of Indices of Multiple Deprivation (IMD). ${ }^{22}$ Another three practices (6, 7 and 8) were also in relatively poor areas, ranking in the top 20-40\% of local authority areas according to IMD, whilst the remaining two practices ( 3 and 4) were of average socio-economic status (Table 2). Research ethical approval was obtained prior to the study, as well as NHS Research and Development approval from each primary care trust relating to the dental practices involved in the study.

In each dental practice, an information sheet about the study, a consent form and a paper copy of the ten-item DVSS questionnaire were given to 40 consecutive patients attending an appointment with a dentist, and also to 40 consecutive patients attending an appointment with a therapist (Table 1). These were distributed by practice staff at the reception desk. No distinction was made relating to the identity of the dentist or dental therapist seen by the patient. It is therefore possible that the patient satisfaction data related to only a few of the dentists/dental therapists working in that practice.

Since delegation practices sometimes varied between dentists working in the same dental practice (with some dentists referring to the dental therapists, and others not), an additional 40 patient questionnaires were distributed to the patients seeing non-referring dentists in these practices (Table 1). Colour coding of questionnaires was used to distinguish between these groups of patients, with 40 blue questionnaires given to patients who saw referring dentists and 40 yellow ones given to dentists who did not refer to the dental therapist. This was to allow investigation as to whether there was any difference in levels of patient satisfaction between these two groups of dentists and also to take account of the possibility that because patients may previously have seen a dental therapist on a previous course of treatment, there may have been some contamination between groups, with patients 


\begin{tabular}{|c|c|c|c|c|c|c|c|c|}
\hline & \multicolumn{2}{|l|}{ Practice size } & \multicolumn{3}{|c|}{ Delegation to dental therapists (DT) } & \multicolumn{3}{|c|}{ Questionnaire distribution } \\
\hline & $\begin{array}{l}\text { Number of } \\
\text { dentists }\end{array}$ & $\begin{array}{l}\text { Number of } \\
\text { dental } \\
\text { therapists }\end{array}$ & $\begin{array}{l}\text { No DT in } \\
\text { the team }\end{array}$ & $\begin{array}{l}\text { All dentists } \\
\text { refer to DT(s) }\end{array}$ & $\begin{array}{l}\text { Only some } \\
\text { dentists refer } \\
\text { to DTs }\end{array}$ & $\begin{array}{l}\text { To patients seen } \\
\text { by referring } \\
\text { dentists }\end{array}$ & $\begin{array}{l}\text { To patients } \\
\text { seen by } \\
\text { non-referring } \\
\text { dentists }\end{array}$ & $\begin{array}{l}\text { To patients } \\
\text { seen by DT }\end{array}$ \\
\hline Practice 1 & 10 & 1 & & & $\checkmark$ & 40 & 40 & 40 \\
\hline Practice 2 & 8 & 3 & & & $\checkmark$ & 40 & 40 & 40 \\
\hline Practice 3 & 1 & 2 & & $\checkmark$ & & 40 & & 40 \\
\hline Practice 4 & 3 & 2 & & $\checkmark$ & & 40 & & 40 \\
\hline Practice 5 & 6 & 2 & & $\checkmark$ & & 40 & & 40 \\
\hline Practice 6 & 3 & 0 & $\checkmark$ & & & & 40 & \\
\hline Practice 7 & 6 & 0 & $\checkmark$ & & & & 40 & \\
\hline Practice 8 & 5 & 1 & & $\checkmark$ & & 40 & & 40 \\
\hline
\end{tabular}

\section{Table 2 Deprivation indices of practices involved in the study}

\begin{tabular}{|l|l|l|l|}
\hline \multirow{2}{*}{ Practice } & \multicolumn{2}{|l}{ National deprivation ward Indices } & IMD quintile \\
\cline { 2 - 4 } & Index of Multiple Deprivation (IMD) & 5,436 & 1 \\
\hline Practice 1 & 37.35 & 352 & 1 \\
\hline Practice 2 & 68.43 & 13,239 & 3 \\
\hline Practice 3 & 20.81 & 15,629 & 3 \\
\hline Practice 4 & 17.75 & 2,110 & 1 \\
\hline Practice 5 & 51.02 & 7,219 & 2 \\
\hline Practice 6 & 32.30 & 10,147 & 2 \\
\hline Practice 7 & 25.87 & 6,505 & 2 \\
\hline Practice 8 & 34.19 & IMV & \\
\hline
\end{tabular}

\section{Table 3 The Dental Visit Satisfaction Scale items}

\section{Information-communication}

1. After talking with the dentist/dental therapist, I know what the condition of my mouth is.

2. After talking with the dentist/dental therapist, I have a good idea of what changes to expect in my dental health in the next few months.

3. The dentist/dental therapist told me all I wanted to know about my dental problem(s).

Understanding-acceptance

4. I really felt understood by my dentist/dental therapist.

5. I felt that this dentist/dental therapist really knew how upset I was about the possibility of pain.

6. I felt this dentist/dental therapist accepted me as a person.

Technical competence

7. The dentist/dental therapist was thorough in doing the procedure.

8. The dentist/dental therapist was too rough when he worked on me.*

9. I was satisfied with what the dentist/dental therapist did.

10. The dentist/dental therapist seemed to know what he was doing during my visit.

*Scored in the opposite direction because of negative content previously seen by a dental therapist making a different judgment concerning their satisfaction with the care provided by a dentist.

The questionnaire instructions asked the patient to complete the questionnaire following their dental treatment that day and then to post their completed questionnaire in the sealed box in the waiting area. Patients were also given an option of using a pre-paid envelope to post the questionnaire directly to the research team if they so wished. Parents were invited to complete the questionnaire on behalf of their children if the appointment was for a child. Only data on the gender of the patient, adult or child and the date of the appointment was collected. In order to preserve anonymity no patient identifiers at all were collected.

The items used in the questionnaire are shown in Table 3. Each of the ten items in the DVSS are written in a five point Likert format with a score ranging from 1 (strongly disagree) to 5 (strongly agree). Rating for patient satisfaction was in a positive direction for all but one item (item 8), with a high score indicating high patient satisfaction. Scoring for item 8 was therefore reversed in the analysis. As well as having an overall patient satisfaction score, the ten items in the DVSS questionnaire can be grouped into three dimensions (information-communication [IC], understanding-acceptance [UA] and perceived technical competence [TC]) with each dimension having 3-4 items as a subscale. The responses to the items in 
each were summed to give a score for the overall scale, and for each subscale. Data was analysed using the Statistical Package for Social Sciences (SPSS), and multilevel analysis was performed using MLwiN. As the number of practices was small, Markov Chain Monte Carlo estimation was used to generate the estimates in MLwiN. The mean scores for the general satisfaction outcome variable and the three sub-scales for patients seeing dentists and patients seeing dental therapists were compared using t-tests.

Multiple regression analysis was undertaken using a range of independent variables: demographic characteristics (patients' age, patients' gender, socio-economic status of the area in which the practice was located), practice characteristics (whether therapists were used by the whole team, part of the team, or not at all) and provider characteristics (whether care provided by a dentist or therapist).

\section{RESULTS}

Four hundred and thirty-one out of the 640 questionnaires distributed were returned (overall response rate 67.3\%). However, a lower proportion of questionnaires to patients seeing dental therapists were returned (54.2\%) than for patients seeing dentists (75.3\%). Within the 431 returned questionnaires, two questionnaires had seven items missing from the ten-item DVSS and were excluded from the results. Another 15 had 1-2 items missing and were replaced with mean values of those items. Therefore 429 questionnaires were used for data analysis in the study. Analysis of the internal consistency of the DVSS indicated a relatively high reliability for the measure, with the Cronbach's alpha coefficient for the overall DVSS 0.906 ( $\mathrm{n}=429)$, and $0.845,0.808$ and 0.781 for the I-C, U-A and TC sub-scales respectively.

As a first stage in the analysis multilevel modelling was undertaken to account for clustering of patients within practices. Only small effects for patient clustering by practice were detected for the overall satisfaction scale, and the results from the multilevel analysis were almost identical to those from the analysis ignoring clustering at practice level. Therefore, for ease of interpretation, the analysis presented here ignores the clustering at practice level. Analysis was undertaken for four outcome

\begin{tabular}{|c|c|c|c|c|c|c|}
\hline \multirow[t]{2}{*}{$\begin{array}{l}\text { DVSS scale and } \\
\text { sub-scales }\end{array}$} & \multirow{2}{*}{$\begin{array}{l}\text { Type of } \\
\text { personnel } \\
\text { visited }\end{array}$} & \multirow{2}{*}{$\begin{array}{l}\text { Number } \\
\text { of } \\
\text { patient } \\
\text { responses }\end{array}$} & \multirow{2}{*}{$\begin{array}{l}\text { Mean score } \\
\text { (standard } \\
\text { deviation) }\end{array}$} & \multirow[t]{2}{*}{$\begin{array}{l}\text { Significance } \\
\text { (2-tailed) }\end{array}$} & \multicolumn{2}{|c|}{$\begin{array}{l}95 \% \text { confidence } \\
\text { interval }\end{array}$} \\
\hline & & & & & $\begin{array}{l}\text { Lower } \\
\text { limit }\end{array}$ & $\begin{array}{l}\text { Upper } \\
\text { limit }\end{array}$ \\
\hline \multirow{2}{*}{$\begin{array}{l}\text { Dental Visit } \\
\text { Satisfaction Scale } \\
\text { (overall) }\end{array}$} & Dentist & 299 & $42.31(5.34)$ & \multirow[t]{2}{*}{$p<0.001$} & \multirow[t]{2}{*}{-4.36} & \multirow[t]{2}{*}{-2.27} \\
\hline & Dental therapist & 130 & $45.62(4.30)$ & & & \\
\hline \multirow{2}{*}{$\begin{array}{l}\text { Information- } \\
\text { communication }\end{array}$} & Dentist & 299 & 12.67 (1.90) & \multirow[t]{2}{*}{$p<0.001$} & \multirow[t]{2}{*}{-1.30} & \multirow[t]{2}{*}{-0.55} \\
\hline & Dental therapist & 130 & $13.60(1.55)$ & & & \\
\hline \multirow{2}{*}{$\begin{array}{l}\text { Understanding- } \\
\text { acceptance }\end{array}$} & Dentist & 299 & 12.45 (1.89) & \multirow[t]{2}{*}{$p<0.001$} & \multirow[t]{2}{*}{-1.38} & \multirow[t]{2}{*}{-0.63} \\
\hline & Dental therapist & 130 & $13.46(1.61)$ & & & \\
\hline \multirow{2}{*}{$\begin{array}{l}\text { Technical } \\
\text { competence }\end{array}$} & Dentist & 299 & $17.18(2.25)$ & \multirow[t]{2}{*}{$p<0.001$} & \multirow[t]{2}{*}{-1.82} & \multirow[t]{2}{*}{-0.94} \\
\hline & Dental therapist & 130 & $18.56(1.81)$ & & & \\
\hline
\end{tabular}

variables: the overall patient satisfaction scale including all the ten items, and the three sub-scales. An initial comparison of the mean scores for general satisfaction and the satisfaction sub-scales between dentists who refer to dental therapists and dentists who do not refer to dental therapists showed no significant differences. Therefore the patient responses relating to dentists referring to dental therapists, and dentists not referring, were put together into one group 'patients attending dentists'. Finally, when the mean satisfaction scores for 'patients attending dentists' and 'patients attending therapists' were compared, statistically significant differences were seen in both the general satisfaction scale and in the three sub-scales (Table 4). All scores showed significantly higher satisfaction levels for patient attending therapists ( $\mathrm{p}<0.001$ ).

A multiple regression analysis was also undertaken with the score for general patient satisfaction and the three subscales as dependent variables, where a higher value stood for a higher degree of satisfaction. Five groups of independent variables were used: visit (care provided by dentists or therapists), practice type and whether all dentists in the team delegate to therapists, only some dentists in the team delegateor therapists not used at all, as well as three demographic characteristics, including the patients' gender (male/ female), patients' age (adult/child), and the socio-economic status of area in which the practice was located (IMD quintile 1, 2 and 3). The results of the regression analysis supported the finding that the distinction between whether the patient visited a dental therapist or a dentist was highly significant (Table 5). 'Visit' significantly associated with both dental visit satisfaction scale and the three subscales I-C, U-A and TC $(\beta=3.038 p<0.05, \beta=0.762$ $\mathrm{p}<0.05, \beta=0.880 \mathrm{p}<0.05, \beta=1.396$ $\mathrm{p}<0.05$, respectively). However, neither the three demographic characteristics nor practice type were found to be significantly associated with patient satisfaction in both the overall satisfaction scale and the three sub-scales, although the regression models did not account for a high proportion of the variability in the data, with adjusted $\mathrm{R}^{2}=0.072$ for the overall satisfaction scale, and $0.033,0.055$ and 0.076 for the sub-scales I-C, U-A and TC.

\section{DISCUSSION}

\section{Strengths and limitations of the study}

As the patients were clustered within practices, it was important to address this in the analysis. Although the number of practices is smaller than is recommended for multilevel analysis, parameter estimates are unbiased even in small samples such as this ${ }^{23}$ if simulation based methods such as MCMC are used, and accurate tests of parameter estimates can then be obtained from a multilevel analysis. As the results from the multilevel analysis were almost identical to those from the single level analysis, only the single level analysis has been presented here.

The findings of this study show clearly that there is a difference in patient 


\begin{tabular}{|c|c|c|c|c|c|c|c|c|}
\hline \multirow[t]{2}{*}{ Independent variables } & \multicolumn{2}{|c|}{$\begin{array}{l}\text { Dental Visit } \\
\text { Satisfaction Scale }\end{array}$} & \multicolumn{2}{|c|}{$\begin{array}{l}\text { Information- } \\
\text { communication }\end{array}$} & \multicolumn{2}{|c|}{$\begin{array}{l}\text { Understanding- } \\
\text { acceptance }\end{array}$} & \multicolumn{2}{|c|}{ Technical competence } \\
\hline & $\beta$ & $p$ value & $\beta$ & $p$ value & $\beta$ & $p$ value & $\beta$ & $p$ value \\
\hline Visit - dentist* & 3.083 & 0.000 & 0.762 & 0.001 & 0.880 & 0.000 & 1.396 & 0.000 \\
\hline \multicolumn{9}{|l|}{ Practice type - no DT* } \\
\hline Use DT in whole team & 0.188 & 0.849 & 0.188 & 0.598 & -0.026 & 0.942 & 0.026 & 0.951 \\
\hline Use DT in part team & -0.436 & 0.735 & -0.070 & 0.881 & -0.479 & 0.309 & 0.113 & 0.836 \\
\hline \multicolumn{9}{|c|}{ Demographic characteristics } \\
\hline Gender - female* & -0.351 & 0.507 & -0.071 & 0.710 & -0.247 & 0.203 & -0.033 & 0.884 \\
\hline Age - child* & -0.507 & 0.580 & -0.034 & 0.919 & -0.113 & 0.736 & -0.360 & 0.356 \\
\hline \multicolumn{9}{|c|}{ Socio-economic status - IMD quintile $3^{*}$} \\
\hline IMD quintile 1 & 0.383 & 0.683 & 0.004 & 0.991 & 0.244 & 0.477 & 0.135 & 0.734 \\
\hline IMD quintile 2 & 0.035 & 0.968 & -0.027 & 0.932 & -0.266 & 0.406 & 0.328 & 0.378 \\
\hline Adjusted $R^{2}$ & \multicolumn{2}{|l|}{0.072} & \multicolumn{2}{|l|}{0.033} & \multicolumn{2}{|l|}{0.055} & \multicolumn{2}{|l|}{0.076} \\
\hline
\end{tabular}

satisfaction between patients reporting on care provided by a dental therapist compared to a dentist. A robust measure of patient satisfaction was used, and the findings were apparent not only for overall satisfaction, but in the areas of information-communication, understanding-acceptance and in technical competence. However, the findings do need to be carefully interpreted. The response rate for patients attending dental therapists was lower than for dentists, and it is possible that non-responders are less satisfied with care. Furthermore, the sample was not randomly drawn from patients attending dental practices: it was a systematic sample of consecutive patients attending for care, from a relatively small number of dental practices. These practices cannot be seen as being generally representative of UK dental practices. In fact the available socio-economic data available indicates that most of the practices were situated in relatively deprived areas. Moreover, previous research has indicated that the failed appointment rate for appointments with dental therapists is higher than for appointments with dentists, ${ }^{24}$ and since the sample was limited to patients attending the practice, non-attending patients (who may have been relatively less satisfied) were not included. Moreover, there was no attempt to control for equivalence of care in the design of the study. No record of the procedure undertaken was made. It is probable that dental therapists may have undertaken some simpler (and perhaps less traumatic) aspects of care than dentists, and so care must to taken before a conclusion is drawn that patients are happier if their care is undertaken by a dental therapist rather than a dentist.

Nevertheless, the findings of this study are of interest, and although patient satisfaction with care by dental therapists has not been previously researched, there are some indications that a differential in patient satisfaction according to the type of personnel carrying out the care does exist. An American study ${ }^{25}$ comparing patients' satisfaction with care by dental hygiene students with patient satisfaction with care by dental students, also reported some differences. Patients were asked to evaluate on a five-point Likert scale six aspects of their dental visit: time, comfort, quality of treatment, operator competence, operator acceptance and operator explanation. For patients receiving 'traditional' (as opposed to 'advanced') periodontal treatment, patients rated dental hygiene students more favourably than the dental students in three aspects ( $\mathrm{p}<0.05)$ : operator explanation, operator competency and operator acceptance. These three aspects are captured in the three sub-scales measured in the DVSS questionnaire: informationcommunication, understanding-acceptance and technical competence, and suggest an interesting pattern may exist.

A greater degree of patient satisfaction with care provided by dental therapists also echoes some of the findings emerging from studies comparing patient satisfaction with care provided by general practitioners (GPs) and nurse practitioners (NPs). Previous reviews of research into patients' perception towards doctors and nurses have suggested that patients tend to be more satisfied with care by nurses than by doctors, especially with their interpersonal skills, time availability and educational and routine aspects of care..$^{26-31}$ Anecdotally, appointments with dental therapists are longer for given procedures than with dentists for the same procedure, and this may be an important factor in influencing patient satisfaction, although there is no evidence to support this, and this may be an interesting avenue for further research. One possible explanation which has been put forward to explain differences in patient satisfaction with care provided by GPs and NPs is that NPs tend to have better interpersonal skills than GPs. It is possible that a similar difference between dentists and therapists exists, and this is detected by patients and influences their judgment of the dental visit. Again, more research is needed.

In all the practices involved in the study levels of patient satisfaction were high, 
with on average patients scoring 'agree' to the ten items on the DVSS scale. There was little variation in patient satisfaction between practices as evidenced by the lack of clustering, and the variable 'seen by dentist/dental therapist' was the most important variable detected which explained variation in levels of patient satisfaction. The fact that the regression model only explained 7\% of the variance in patient satisfaction is not surprising. Previous studies in general medical practice show that between 90\% and 95\% of the variance in patient satisfaction is explained at the patient level, with the remaining $5 \%$ to $10 \%$ at the doctor or practice level. ${ }^{32}$ Although some demographic factors such as the patient's gender and the socio-economic profile of the area in which the practice was situated, were entered into the regression model, there are many more patient-related factors not considered that may have been relevant (the previous dental history of the patient, level of dental anxiety etc). The type of treatment involved would have also been an important variable, although not included in this study. The findings do therefore point towards considering the findings as an expression of the construct which is patient satisfaction, through the lens of the theories which underpin this concept.

Theories governing patient satisfaction have mainly emerged from the fields of marketing, psychology and health service research, initially being applied to the study of consumer satisfaction, and more recently to the study of patient satisfaction. Expectation theories are considered to be the most important, with attribution and equity theories also making a contribution. ${ }^{33}$ Disconfirmation theory was one of the first theories to be developed to explain attitudes related to consumer satisfaction. This theory suggests that consumers compare the actual attribute performance (ie an aspect of care) with their pre-consumption expectations. ${ }^{34}$ The difference between the expectation and performance is called disconfirmation. Disconfirmation theory suggests that if all things are equal, the higher expectations are, the harder it is for performance to meet or exceed them. This means that satisfaction can effectively be reduced by a higher expectation. A zone of tolerance also exists, which is the range between desired and adequate expectation. The 'desired expectation' is the level of service the consumers hope to achieve; the 'wish for' level of performance blending what consumers believe 'can be' and 'should be'. When consumers recognise the desired expectations are not always achievable, they will hold to a lower level of expectation - 'adequate expectation' which is the minimum tolerable expectation. ${ }^{34}$ The zone of tolerance is thought to vary between attributes of care, with a wider zone of tolerance for less important aspects. ${ }^{35,36}$ On this basis, a possible explanation of the difference found between patients' evaluation of the care provided by dentists and dental therapists may be that patients' expectations of care provided by dental therapists may be relatively low compared to their expectations of dentists' care, and after being treated by a therapist patients find their level of expectation exceeded. One could however also argue that the zone of tolerance for work done by a dental therapist (more routine work) might be narrower than for work done by a dentist. This would mean a more demanding level of patient expectation would exist when patients were treated by dental therapists, which does not appear to be the case, although further work on the expectations of patients is required.

Some authors have challenged the notion of patient satisfaction as a dichotomy of 'ideal' and 'practical' expectations, suggesting that a more complex process of evaluation of care exists involving concepts of 'duty' and 'culpability. ${ }^{37}$ These concepts feature in attribution theories of patient satisfaction, which are concerned with what the product or services should do, and who is to blame if failure occurs. These theories suggest that even where the experience of contact with the service is negative, a person's evaluation of the service may still be positive if the service provider is not seen as responsible for the failure in service, and this may have relevance in interpreting the outcomes of surveys of patient satisfaction in dental practice, where the dentist is legally liable for all care provided by the team.

\section{IMPLICATIONS OF THE STUDY}

These findings may provide some reassurance for dentists considering employing a dental therapist in their practice. Concerns about patient acceptability are reported to be one barrier to the employment of dental therapists in dental practice, ${ }^{38}$ and whilst this may reflect issues concerned with the wider social acceptability of delegation within the dental team, these findings provide something of a counter-argument. Whilst in other countries, the role of dental therapists may differ from the role carried out traditionally by therapists in the UK, similar differences between patients' evaluation of the care provided by dentists and therapists may exist, and further work needs to be done to explore this area. There are other dental team members too, such as dental hygienists and dental nurses with extended duty roles, where differences in patient satisfaction may be apparent, and this also merits investigation. In conclusion therefore, this study was an exploratory study, and the first of its kind in this area. It has revealed an interesting phenomenon, but one which needs to be interpreted with care by undertaking further study.

The authors would like to thank all the practices involved in the study for their kind collaboration. The study was funded by Central Lancashire Primary Care Trust.

1. Nuffield Foundation. Inquiry into dental education. London: Nuffield Foundation 1980

2. Department of Health. NHS dentistry: options for change. London: Department of Health 2002.

3. Nuffield Foundation. Education and training of personnel auxiliary to dentistry. London: Nuffield Foundation, 1993.

4. General Dental Council. Scope of practice - who can do what in the dental team. London: General Dental Council, 2009.

5. Harris R V, Haycox A. The role of team dentistry in improving access to dental care in the UK. Br Dent J 2001; 190: 353-356

6. Atkin $\mathrm{K}$, Hirst M, Lunt N, Parker G. The role and self-perceived training needs of nurses employed in general practice: observations from a national census of practice nurses in England and Wales. J Adv Nurs 1994; 20: 46-52.

7. Sutton M, McLean G. Determinants of primary medical care quality measured under the new UK contract: cross-sectional study. BMJ 2006; 332: 389-390.

8. Laurant M, Reeves D, Hermens R, Braspenning J Grol R, Sibbald B. Substitution of doctors by nurses in primary care. Cochrane Database Syst Rev 2005; (2): CD001271.

9. Hewitt C, Lankshear A, Maynard A, Sheldon T, Smith K. Health service workforce and health outcomes: a scoping study. Final report SD0/50/2003. National Health Service Research and Development Service Delivery and Organisation programme, 2003.

10. Allred H. Assessment of the quality of dental care London: London Hospital Medical College, 1977.

11. Holt R D, Murray J J. An evaluation of the role of the New Cross dental auxiliaries and of their contribution to the Community Dental Services. BrDent J 1980; 149: 259-262

12. Sitzia J, Wood N. Patient satisfaction: a review of issues and concepts. Soc Sci Med 1997; 45: $1829-1843$. 
13. NHS Management Inquiry. London: Department of Health and Social Security, 1984.

14. Mascarenhas A K. Patient satisfaction with the comprehensive care model of dental delivery. J Dent Educ 2001; 65: 1266-1271.

15. Carr-Hill R A. The measurement of patient satisfaction. J Public Health Med 1992; 14: 236-249.

16. Cardozo R. An experimental study of consumer effort, expectation and satisfaction. J Market Res 1965; 2: 244-249.

17. Newsome PR H, Wright G H. A review of patient satisfaction: 1. Concepts of satisfaction. Br Dent J 1999; 186: 161-165.

18. Ware J E Jr, Davies-Avery A, Stewart A L. The measurement and meaning of patient satisfaction: a review of the recent literature. Health and Medical Care Services Review 1978; 1: 1-15.

19. Corah N L, O'Shea R M, Pace L F, Seyrek S K. Development of a patient measure of satisfaction with the dentist: the dental visit satisfaction scale. J Behav Med 1984; 7: 367-373

20. Wolff M H, Putnam S M, James S A, Stiles W B. The medical interview satisfaction scale: development of a scale to measure patients perceptions of physicians' behaviour. J Behav Med 1978; 1: 391-401.

21. Yin R K. Case study research: design and methods. Newbury Park, CA: Sage, 1984

22. Communities and Local Government website. Indices of deprivation 2007 http://www.communities.gov.uk/communities/ neighbourhoodrenewal/deprivation/deprivation07/.

23. Maas C J M, Hox J J. Sufficient sample sizes for multilevel modeling. Methodology 2005; 1: 86-92.

24. Harris R, Burnside G. The role of dental therapists working in four personal dental service pilots: type of patients seen, work undertaken and cost-effectiveness within the context of the dental practice. Br Dent J 2004; 197: 491-496.

25. Sisty N L, Henderson W G. A comparative study of patient evaluations of dental treatment performed by dental and expanded-function dental hygiene students. J Am Dent Assoc 1974; 88: 985-996.

26. Laurant $M$, Hermens $R$, Braspening J, Akkermans $R$, Sibbald B, Grol R. An overview of patients' preference for, and satisfaction with, care provided by general practitioners and nurse practitioners. J Clin Nurs 2008; 17: 2690-2698.

27. Brown SA, Grims D E. A meta-analysis of nurse practitioners and nurse midwives in primary care. Nurs Res 1995; 44: 332-339.

28. Harrocks S, Anderson E, Salisbury C. Systematic review of whether nurse practitioners working in primary care provide equivalent care to doctors. BMJ 2002; 324: 819-823.

29. Mckenna H P. Nursing skill mix substitutions and quality of care: an exploration of assumptions from the research literature. J Adv Nurs 1995; 21: 452-459.

30. Bredart $A$, Coens $C$, Aaronson N et al. Determinants of patient satisfaction in oncology settings from European and Asian countries: preliminary results based on the EORTC IN-PATSAT32 questionnaire. Eur J Cancer 2007; 43: 323-330.

31. Redsell S, Stokes T, Jackson C, Hastings A, Baker R. Patients' accounts of the differences in nurses' and general practitioners' roles in primary care. $J A d v$ Nurs 2007; 57: 172-180.

32. Sixma H J, Spreeuwenberg P M, van der Pasch $M$ A. Patient satisfaction with the general practitioner: a two-level analysis. Med Care 1998; 36: $212-229$.

33. Ware J E Jr, Davies-Avery A, Stewart A L. The measurement and meaning of patient satisfaction. Health Med Care Serv Rev 1978; 1: 1-15.

34. Zeithaml V, Bitner M. Services marketing. New York: McGraw-Hill, 1996.

35. Parasuraman A, Berry L, ZeithamI V. Understanding customer expectations of service. Sloan Management Rev 1991; 32: 39-48.

36. Alford B L. Affect, attribution, and disconfirmation: their impact on health care services evaluation. Health Mark 0 1998; 15: 55-74.

37. Williams B, Coyle J, Healy D. The meaning of patient satisfaction: an explanation of high reported levels. Soc Sci Med 1998; 9: 1351-1359.

38. Gallagher J L, Wright D A. General dental practitioners' knowledge of and attitudes towards the employment of dental therapists in general practice. Br Dent J 2003; 194: 37-41. 